\title{
Using estimation methods to close gaps in databases for the modelling of radionuclide solubilities in brines SVEN HAGEMANN
}

Gesellschaft für Anlagen- und Reaktorsicherheit

Presenting Author: sven.hagemann@grs.de

In many countries, it is planned to dispose of radioactive waste in deep geological formations. Depending on the host rock and site, highly saline waters occur that may mobilise and transport radionuclides and other contaminants. In such systems, specific ion interactions cannot be neglected. For the calculation of solubilities, suitable models, such as Pitzer's model, need to be used. The experimental challenges for determining Pitzer interaction coefficients are often high so that they are not yet available for many aqueous species and reliable solubility calculations are not yet feasible. In such a situation, data estimation is a justifiable way to close existing gaps.

For the elements $\mathrm{Mo}, \mathrm{Ni}, \mathrm{Pb}, \mathrm{Pd}, \mathrm{Se}, \mathrm{Sn}$, and $\mathrm{Sm}$, missing thermodynamic data are identified. This mainly concerns complex species such as chlorine and hydroxo complexes. Various correlation and analogy models (e.g. [1]) are discussed and selected for application. These approaches are then used to derive stability constants and interaction coefficients for the identified species. The new data are combined with existing databases (e.g. [2], [3]) and applied to model solubility experiments in a broad $\mathrm{pH}$ range in different salt solutions.

The agreement between modelling and experiment is often surprisingly good. The deviations are mostly in the range of up to 1.5 orders of magnitude. This is considerable progress compared to earlier, far less accurate solubility estimates [4]. In the context of long-term safety analyses, numerical uncertainties of this magnitude may be sufficient, as radionuclide solubilities represent only a small fraction of the total amount of all variable factors. Significantly larger deviations may be an indication of previously unrecognised stable complexes (e.g. ternary calciumhydroxo complexes), uncertainties in thermodynamic stability data, or analytical difficulties that need to be investigated further.

[1] Simoes, Hughes et al. (2016) J. Chem. Eng. Data 61, 2536-2554.

[2] Moog, Bok et al. (2015) Appl. Geochem. 55, 72-84.

[3] Hagemann (2012) GRS-Bericht 219.

[4] Buhmann, Nies \& Storck (1991) GSF-Bericht 27/91.

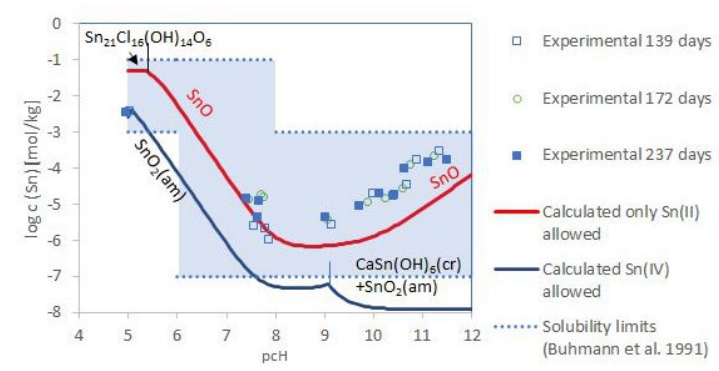

